\title{
Carbohydrate analysis by methanolysis method and application to compositional analysis of transparent exopolymer particles
}

\author{
Shigeki Wada ${ }^{1,2^{*}}$, Kazuo Iseki ${ }^{3}$, Takeo Hama ${ }^{1}$ \\ ${ }^{1}$ Life and Environmental Sciences, University of Tsukuba, Tsukuba, Japan \\ ${ }^{2}$ Shimoda Marine Research Center, University of Tsukuba, Shimoda, Japan \\ ${ }^{3}$ Graduate School of Biosphere Science, Hiroshima University, Hiroshima, Japan

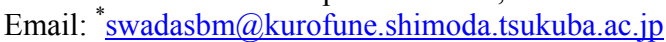

Received 6 July 2013; revised 7 August 2013; accepted 21 August 2013

Copyright (C) 2013 Shigeki Wada et al. This is an open access article distributed under the Creative Commons Attribution License, which permits unrestricted use, distribution, and reproduction in any medium, provided the original work is properly cited.

\begin{abstract}
Measurement of uronic acids (URAs) which are a group of acidic sugar, would be useful for the understanding of dynamics of bacterial extracellular polymeric substances (EPS) in marine environments. However, the URA analysis using traditional hydrolysis method which is used for neutral sugar analysis poses serious problems in URA that is unstable under hydrolysis. We developed the methanolysis method, which deploymerizes polysaccharides while retaining quantitative information. Our method was applied to coastal seawater, and the URAs distribution was compared with that of transparent exopolymer particles (TEP) which are acidic sugar containing particles. Since the relationship of URA with TEP was relatively weak, URA-containing polysaccharides present in bacterial EPS would not participate as a structural component of TEP.
\end{abstract}

Keywords: Uronic Acid; Transparent Exopolymer Particles; Methanolysis; Gas Chromatography Mass Spectrometry

\section{INTRODUCTION}

Quantitative and qualitative analyses of carbohydrates in seawater provide some information on dynamics of organic matter such as its origin and diagenetic processes [1-3], as well as its vertical transport and sedimentation [4-6]. Monosaccharides characterized in these studies were mainly neutral sugars (NSs), which comprise a major group of carbohydrates, but there are other minor sugar groups such as uronic acids (URAs). Although

"Corresponding author.
URA, a carboxylated acidic sugar, has minor contribution to total carbohydrates in most cases, it is known as an important component of bacterial extracellular polymeric substances (EPSs) $(20 \%-50 \%$ of total carbohydrate: $[7,8])$, and URA measurements are likely to reflect the dynamics of bacterial EPSs in a water column. EPSs readily adhere to each other as a result of their pronounced stickiness [9], and constitute amorphous aggregates such as transparent exopolymer particles (TEPs), which are defined as particles containing acidic sugar $[10,11]$. Since TEPs are relevant to sinking particle formation and the supply of food to filter feeders [11-14], URA measurements should allow us to better understand the contribution of bacterial EPSs to these processes.

Analysis of neutral sugars has been achieved by using chromatographic measurements after depolymerization under acid hydrolysis reaction [15]. On the other hand, application of acid hydrolysis method to URA analysis has some problems, because URA, once released after hydrolysis, forms lactones irreproducibly [16]. To overcome this, it is necessary to correct the recovery yield of URA after hydrolysis reaction, or to use other depolymerization method. In the present study, we apply the methanolysis method, which depolymerizes polysaccharides using methanolic $\mathrm{HCl}$. High recovery yields for authentic standards and some plant materials were achieved by some previous researchers $[17,18]$, but the suitability of the methanolysis method for marine environmental samples has yet to be examined.

In the present study, we modified a previous methanolysis method for the determination of URA in seawater samples $[17,18]$. In addition, we examined the monosaccharide composition of natural seawater sample in a coastal environment using the methanolysis method, and compared the distribution of URA in the water column 
with that of TEP to understand the contribution of URA to aggregate formation.

\section{MATERIALS AND METHODS}

\subsection{Sample Collection}

In 2007, seawater samples were collected from a coastal region at a station in Suo-Nada (30 m depth, 131,16E, $33,49 \mathrm{~N}$ ) during the fifth cruise of the TRV Toyoshio Maru of Hiroshima University in July, 2007. Seawater was collected from 1, 5, 10, 15, 20 and $25 \mathrm{~m}$ using a Rosette sampler fitted with Niskin bottles. The samples were filtered through precombusted $\left(450^{\circ} \mathrm{C}, 4 \mathrm{~h}\right)$ glass fiber filters (Whatman GF/F) and the filters were stored at $-20^{\circ} \mathrm{C}$ until analysis. In the present study, we carried out duplicate analyses for the samples at each depth.

\subsection{Derivatization}

The experimental scheme is a modification of the methods of Doco et al. (2001) and [19]. For analysis of particulate carbohydrates, chopped filter samples were placed in a $10 \mathrm{ml}$ glass tube, and internal standard (myoInositol) was added. We putted the tube in a vacuum desiccator with phosphorous oxide (V) for 1 day to remove any water completely. After adding $2 \mathrm{ml} 0.5 \mathrm{~N}$ methanolic $\mathrm{HCl}$ (mixture of $15 \mathrm{ml} \mathrm{MeOH}$ with $0.4 \mathrm{ml}$ acetyl chloride) to the dried pellets, the tubes were sonicated for $15 \mathrm{~min}$, sealed tightly and heated at $80^{\circ} \mathrm{C}$ for 24 $\mathrm{h}$ (methanolysis reaction). After cooling to room temperature, the samples were centrifuged and the supernatant was transferred to another test tube. $\mathrm{MeOH}(1 \mathrm{ml})$ was added to the tube with chopped filter. The tube weresonicated for a few s, centrifuged, and resulting supernatant was combined with the previous one (this procedure was repeated $2 \times$ ). After addition of $20 \mu$ pyridine for neutralization of the supernatant, the samples were dried under an $\mathrm{N}_{2}$ stream at $40^{\circ} \mathrm{C}$ and stored in a vacuum desiccator with phosphorus oxide (V) for 3 days. Since the reagents for trimethylsilylation are readily decomposed by water, complete removal of water from the samples was checked.

TMSi-H [hexamethyldisilazane/trimethylchlorosilane/ pyridine, 2/1/10 (v/v/v), GL Science] was added $(0.2 \mathrm{ml})$ to the dried samples and the tubes were heated at $80^{\circ} \mathrm{C}$ for $2 \mathrm{~h}$ for the conversion to TMS derivatives. After cooling to room temperature, the samples were dried under an $\mathrm{N}_{2}$ stream at $40^{\circ} \mathrm{C}$ and the dried pellets were dissolved in hexane and sonicated for a few $\mathrm{s}$. The tubes were centrifuged and the supernatant was injected into a gas chromatograph/mass spectrometer within $24 \mathrm{~h}$ after trimethylsilylation at room temperature, because the derivatized sample becomes unstable a few days after the reaction. Standard materials for calibration also underwent methanolysis and trimethylsilyl reactions as well as the natural samples.

\subsection{Analysis with Gas Chromatography/Mass Spectrometry}

GC/MS (QP 2050, Shimadzu) used an HP-1 fused silica column $(30 \mathrm{~m} \times 0.25 \mathrm{~mm}$ i.d., $0.25 \mathrm{~mm}$ film thickness, Hewlett Packard) and the electron impact ionization (EI) mode. The detailed analytical condition were: inlet and interface temperature $250^{\circ} \mathrm{C}$, ion source temperature $200^{\circ} \mathrm{C}$ : column oven temperature programme $50^{\circ} \mathrm{C}(1$ $\min )$, to $120^{\circ} \mathrm{C}$ at $50^{\circ} \mathrm{C} \cdot \mathrm{min}^{-1}$, to $145^{\circ} \mathrm{C}$ at $1^{\circ} \mathrm{C} \cdot \mathrm{min}^{-1}$, to $200^{\circ} \mathrm{C}$ at $0.9^{\circ} \mathrm{C} \cdot \mathrm{min}^{-1}$, to $230^{\circ} \mathrm{C}$ (held $10 \mathrm{~min}$ ) at $10^{\circ} \mathrm{C} \cdot \mathrm{min}^{-1}$ in order to separate eight NSs i.e. arabinose (Ara), ribose (Rib), rhamnose (Rha), fucose (Fuc), xylose (Xyl), mannose (Man), galactose (Gal) and glucose (Glc), and two URAs, galacturonic acid (Gal Ac) and glucuronic acid (Glc Ac) (Table 1). We confirmed the retention time by measuring authentic standards one by one; D-Arabinose (Wako), D-Ribose (Pfanstiehl Laboratories Inc), L-Rhamnose monohydrate (Wako), L-Fucose (Pfanstiehl Laboratory Inc), D-Xylose (Wako), D-Mannose (Wako), D-Galactose (Wako), D-Glucose (Wako), D-Galacturonic acid (Wako), and D-Glucuronic acid (Wako).

Table 1. Retention times of each monosaccharide.

\begin{tabular}{|c|c|}
\hline Name of Sugar & Retention time (min) \\
\hline Arabinose (1) & $14.30 \pm 0.021$ \\
\hline Arabinose (2) & $14.82 \pm 0.022$ \\
\hline Ribose (2) & $15.00 \pm 0.020$ \\
\hline Ribose (1) & $15.70 \pm 0.021$ \\
\hline Rhamnose (1) & $16.01 \pm 0.021$ \\
\hline Rhamnose (2) & $16.33 \pm 0.019$ \\
\hline Fucose (1) & $17.22 \pm 0.024$ \\
\hline Fucose (2) & $18.46 \pm 0.023$ \\
\hline Xylose (1) & $19.78 \pm 0.021$ \\
\hline Xylose (2) & $21.09 \pm 0.027$ \\
\hline Glucuronic acid (2) & $24.88 \pm 0.029$ \\
\hline Mannose (1) & $30.32 \pm 0.029$ \\
\hline Mannose (2) & $32.20 \pm 0.031$ \\
\hline Galactose (1) & $33.51 \pm 0.035$ \\
\hline Galacturonic acid (1) & $34.64 \pm 0.029$ \\
\hline Galacturonic acid (2) & $35.19 \pm 0.032$ \\
\hline Galactose (2) & $36.06 \pm 0.028$ \\
\hline Glucose (1) & $37.69 \pm 0.038$ \\
\hline Glucuronic acid (1) & $39.06 \pm 0.036$ \\
\hline Glucose (2) & $39.90 \pm 0.036$ \\
\hline Internal Standard (myo-Inositol) & $57.74 \pm 0.217$ \\
\hline
\end{tabular}

Peaks of two isomers were quantified in the present study, and order of peak intensity between the two isomers was indicated with number in parenthesis (higher peak: (1), lower peak: (2)). 
Three fragment ions $(\mathrm{m} / \mathrm{z}=204$ and 217 in $10-24.75$ and $25.8-100 \mathrm{~min}$, and $\mathrm{m} / \mathrm{z}=204$ and 230 in $24.75-$ $25.8 \mathrm{~min}$ ) commonly found in the mass spectra of TMS derivatives of carbohydrates when EI is used were monitored in the selective ion monitoring (SIM) mode [19]. The methanolysis reaction theoretically generates $4-6$ isomers from each monosaccharide, but it is difficult to quantify all of the isomers because some minor peaks were too small to quantify. Since the generation patterns of isomers would be constant if the condition (temperature and time) of methanolysis reaction does not change as described in latter section, we choose the highest and second highest peaks for quantification in most case. For galactose, the 1 st and 3 rd peak were quantified in the present study, because the 3rd highest peak of mannose coeluted with the 2 nd highest one of galactose. The analytical errors (coefficients of variance between duplicate analyses) for each monosaccharide were $0.81 \%$ - 36\%, and mostly the values were around 10\% (Table 2).

\subsection{Analyses of Particulate Organic Carbon and TEP}

Particulate organic carbon (POC) concentration was determined using an elemental analyzer (FISONS EA 1108). For analysis of TEP concentration, $70 \mathrm{ml}$ of seawater samples were filtered through polycarbonate filter (Millipore) with pore size of $0.4 \mu \mathrm{m}$, and immediately stained by prefiltered alcian-blue solution $(0.2 \mu \mathrm{m}, 0.02 \%$ alcian blue $8 \mathrm{GX}$ in $0.06 \%$ acetic acid) which stains acidic sugar. The filters were transferred into $80 \% \mathrm{H}_{2} \mathrm{SO}_{4}$ for $2 \mathrm{~h}$, and the absorption at $787 \mathrm{~nm}$ was measured. The TEP concentration operationally defined as alcian bluestained particles of size $>0.4 \mu \mathrm{m}[10,20]$, were measured colorimetrically according to the method of Passow and Alldredge [20]; the concentration was normalized with a gum xanthan equivalent per liter (GX equiv. $1^{-1}$ ).

\section{RESULTS \& DISCUSSION}

When applying the methanolysis method to seawater samples, it is essential to take account of the presence of various organic compounds as concomitants, which cannot be completely separated from carbohydrates. Application of the EI/SIM mode in GC/MS enables us to minimize the possible effect from non-carbohydrate compounds which overlap with target compounds during the GC separation, since only the specific fragment ions for carbohydrates [19] were monitored in the present study, as described above. We have conducted preliminary measurements using GC-FID, which detects organic compounds non-selectively to estimate their concentrations. However, some of the monosaccharides cannot be quantified due to the overlap with concomitant peaks (data not shown). Thus, the application of selective detection in the GC/MS would be preferable for the analysis of the concentrations of carbohydrates using the methanolysis method.

Although 4 - 6 isomers theoretically occur from each monosaccharide, it is operationally difficult and laborious to detect all the isomers including minor ones. Since the generation patterns of isomers would be constant regardless of their initial form such as anomeric or ring size configurations of the carbohydrates before derivatization [19], we measured only the highest and second highest peaks in the present study. If such selection of major peak was appropriate for quantitative analysis, ratios of peak area of the second highest peak to the first one would be similar between authentic standards and environmental samples. Therefore, we also checked the isomeric ion composition (ratios of second highest peak against first one) between standard compounds used for calibration and natural sample. In conclusion, the isomer composition was similar between them (Table 3).

Concentrations of POC and TCHOs (sum of 8 NSs and 2 URAs) decreased from 24,000 - 26,000 and $3200-$ $4000 \mathrm{nM} \mathrm{C}$ in surface layer $(1-10 \mathrm{~m})$ to $14,000-21,000$ and 1300 - $2000 \mathrm{nM} \mathrm{C}$ in bottom layer (15 - $25 \mathrm{~m}$ ) (Figures 1(a) and (b)). The proportions of TCHO to POC were $8.4 \%$ - $16 \%$, and the value was higher in the surface layer (1 - $10 \mathrm{~m}$ : 13\% - 16\%, 15 - $25 \mathrm{~m}: 8.4 \%$ - 13\%). These results for profiles of TCHO concentration and contribution of TCHO to POC were generally consistent

Table 2. Error ranges of duplicate samples.

\begin{tabular}{ccccccccccccc}
\hline Depth $(\mathrm{m})$ & Ara & Rib & Rha & Fuc & Xyl & Glc Ac & Gal Ac & Man & Gal & Glc & TCHO \\
\hline 1 & 11.7 & 30.2 & 20.3 & 17.6 & 11.7 & 4.93 & 5.89 & 4.38 & 4.37 & 8.62 & 0.808 \\
5 & ND & ND & ND & ND & ND & ND & ND & ND & ND & ND & ND \\
10 & 4.08 & 21.2 & 5.51 & 4.10 & 3.75 & 6.15 & 4.46 & 1.99 & 1.07 & 0.697 & 5.40 \\
15 & 5.01 & 16.8 & 8.74 & 7.00 & 10.5 & 10.1 & 9.34 & 16.5 & 0.909 & 11.0 & 11.3 \\
20 & 6.55 & 1.02 & 13.9 & 11.6 & 5.51 & 12.1 & 17.9 & 24.6 & 10.9 & 1.58 & 13.1 \\
25 & 16.0 & 5.82 & 36.2 & 25.6 & 18.7 & 3.24 & 3.77 & 10.1 & 0.810 & 2.73 & 11.4 \\
\hline
\end{tabular}

Values are coefficient of variance between duplicate analysis. ND means not determined because single data was obtained for the sample at $5 \mathrm{~m}$ depth. 
Table 3. Isomer ratios of each monosaccharide.

\begin{tabular}{ccc}
\hline & Standard $(\mathrm{n}=7)$ & Samples $(\mathrm{n}=6)$ \\
\hline Arabinose & $60 \pm 12$ & $57 \pm 2.2$ \\
Ribose & $11 \pm 2.1$ & $17 \pm 3.4$ \\
Rhamnose & $7.6 \pm 1.1$ & $26 \pm 2.4$ \\
Fucose & $38 \pm 2.5$ & $50 \pm 3.3$ \\
Xylose & $49 \pm 2.0$ & $49 \pm 1.5$ \\
Mannose & $7.1 \pm 1.0$ & $7.3 \pm 0.63$ \\
Galactose & $34 \pm 2.8$ & $38 \pm 2.6$ \\
Glucose & $38 \pm 1.0$ & $39 \pm 2.7$ \\
Galacturonic acid & $42 \pm 6.7$ & $67 \pm 9.8$ \\
Glucuronic acid & $38 \pm 1.2$ & $39 \pm 8.8$ \\
\hline
\end{tabular}

The values are peak area ratios of 2 nd abundant isomer to 1 st one for each monosaccharide. The column of standard indicates the values of authentic standard which is measured for calibration. Samples indicate the average values of among the samples from all the depths $(1,5,10,15,20$ and $25 \mathrm{~m})$.

with those in previous findings [21-25]. The carbohydrate concentrations decreased more sharply with depth than bulk POC (Figures 1(a) and (b)), indicating that carbohydrates are relatively reactive components, as shown in other studies [1-3,26,27].

Concentrations of Gal Ac and Glc Ac in POM from surface seawater $(1-10 \mathrm{~m}$ depth) were $22-30$ and 29 $40 \mathrm{nM} \mathrm{C}$, respectively, slightly higher than those in the bottom layer (15 - $25 \mathrm{~m}$; Gal Ac and Glc Ac, 16 - 26 and 14 - $25 \mathrm{nM} \mathrm{C}$, respectively) (Figure 1(c)). Total URA (Gal Ac and Glc Ac concentrations) were $30-70 \mathrm{nM} \mathrm{C}$, accounting for $0.19 \%-0.29 \%$ and $1.5 \%-2.5 \%$ of POC and particulate $\mathrm{TCHO}$, respectively. In the previous studies, distributions of URA in POC have been investigated with the colorimetric method $(1.4 \%-4.5 \%, 4.7 \%$ $23 \%[28,29])$, being comparable with those in the present study. The trends in vertical profiles in the mol percentages of URA species in TCHO differed between Gal Ac and Glc Ac. Gal Ac in particulate TCHO accounted for $0.67 \%-0.79 \%$ in the surface layer ( $1-10 \mathrm{~m}$ depth), relatively lower than that in the bottom layer $(0.90 \%-1.3 \%)$. On the other hand, the contribution of Glc Ac to particulate $\mathrm{TCHO}$ was $0.80 \%-1.2 \%$, with no distinctive vertical trend in Suo-Nada (Figure 2(a)).

The dynamics of NS components were also different among each component (Figures 1(d) and (e)). Glucose fractions in the particulate TCHO decreased with depth from $27 \%-34 \%(1-10 \mathrm{~m})$ to $20 \%-23 \%(15-25 \mathrm{~m})$ (Figure 2(b)), while other monosaccharides components were mostly constant or increased with depth (constant: Rha and Gal, increase: Ara, Rib, Fuc, Xyl and Man) (Figures 2(b) and (c)). Most of the glucose would origi- nate from glucan, a carbohydrate reserved in phytoplankton [30]. Since glucan is considered as one of the most bio-labile components of OM derived from phytoplankton [3,31], it is conceivable that the glucan produced in surface layers by phytoplankton is rapidly decomposed during export to depth.

Transparent exopolymer particles (TEPs) are operationally defined as those above $0.4 \mu \mathrm{m}$ when stained by alcian blue, a binding dye for acidic sugars, including URAs $[10,11]$. Since TEPs are likely to promote sinking particle formation and bacterial colonization in water columns, their biogeochemical and ecological importance in marine environments has been intensively studied $[11,14,32]$. In the present study, the depth profiles of TEPs showed that their concentrations ranged from 20 to $100 \mu \mathrm{g}$ GX equiv. $~^{-1}$ (Figure 3), and decreased from the surface with depth. The concentrations and depth profiles are comparable to those from previous studies of coastal

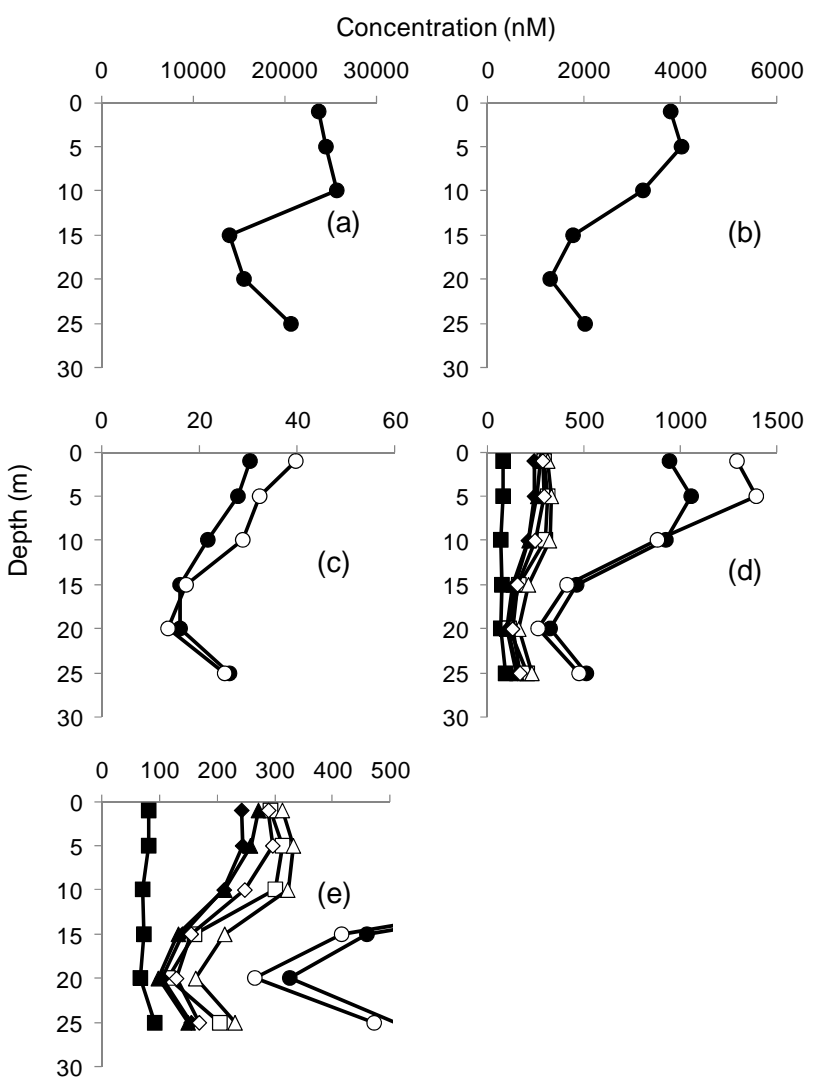

Figure 1. Vertical profiles of concentrations of POC, total carbohydrates, uronic acids (Gal Ac and Glc Ac) and neutral sugars. The ordinate and abscissa indicate depth $(\mathrm{m})$ and concentrations (nM). The profiles of POC (a), total carbohydrates (b), each uronic acid (galacturonic acid $(\bullet)$ and glucuronic acid (०)) (c), each neutral sugar (arabinose $(\boldsymbol{\square})$, ribose $(\square)$, rhamnose $(\boldsymbol{\Delta})$, fucose $(\triangle)$, xylose $(\diamond)$, mannose $(\diamond)$, galactose $(\bullet)$, and glucose $(\circ))(\mathrm{d}$ and e) were shown. The abscissa of the fifth figure (e) is zoomed to show the minor components. 
ecosystems (Monterey Bay and Santa Barbara Channel, 6 - $270 \mu \mathrm{g}$ GX equiv. $1^{-1}$; [20]).

We had hypothesized that the concentrations of TEPs and particulate URAs have a close mutual relationship, given that the amounts of binding dye would be proportional to acidic sugar content [33]. However, the concentration of TEPs showed a relatively weak relationship with those of particulate URAs when compared with NSs in Suo-Nada (Table 4), even though URAs are one of the well-known acidic sugar groups. This suggests that the contribution of URAs to TEPs is a lesser one, making it essential to consider the contribution of other acidic sugar components such as sulfated carbohydrates. There have been just a few studies on the comparison between URA and sulfated carbohydrates so far [34,35], and they had found abundant formation of TEP, high stickness of aggregates, and higher contribution of sulfated carbohydrates compared with URA. Considering these finding together with our results, sulfated carbohydrate could be a major acidic sugar component in TEPContents of URA and sulphates in EPS would be variable among source organisms. Since it has been suggested that bacterial EPSs are relatively abundant in URA compared with phytoplanktonic EPSs [8], URA-containing polysaccharides present in bacterial EPS don't participate as structural components of TEP.

Table 4. Relationships of each monosaccharide and TEP concentrations.

\begin{tabular}{ccc}
\hline Arabinose & $\mathrm{r}^{2}$ & \\
Ribose & 0.0018 & Not significant \\
Rhamnose & 0.619 & Not significant \\
Fucose & 0.740 & $<0.05$ \\
Xylose & 0.688 & $<0.05$ \\
Mannose & 0.733 & $<0.05$ \\
Galactose & 0.738 & $<0.05$ \\
Glucose & 0.720 & $<0.05$ \\
Galacturonic acid & 0.726 & $<0.05$ \\
Glucuronic acid & 0.239 & Not significant \\
TCHO & 0.539 & Not significant \\
POC & 0.728 & $<0.05$ \\
\hline
\end{tabular}

Mol percentages (\%)

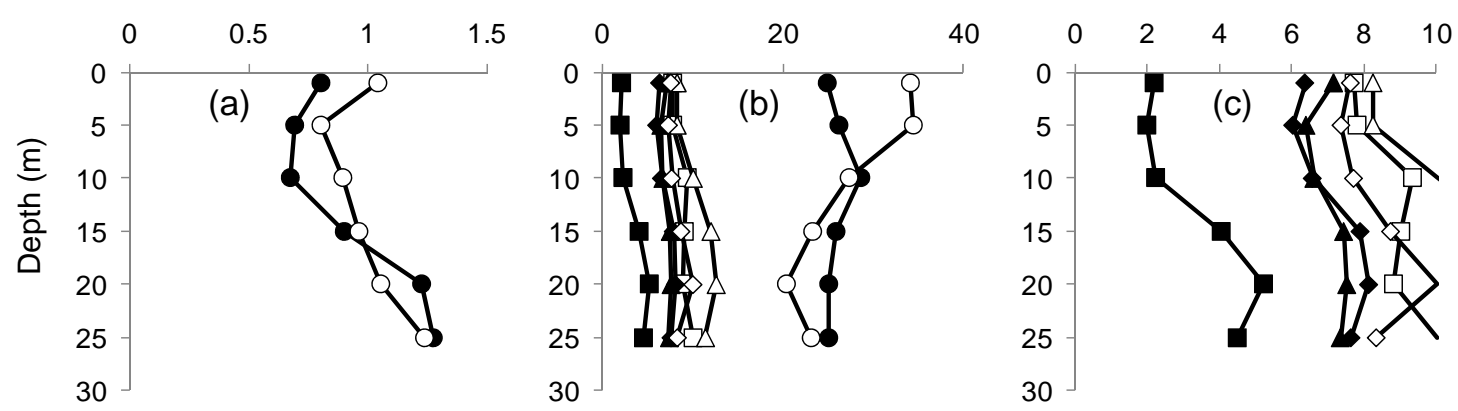

Figure 2. Vertical profiles of proportions of each monosaccharide. The ordinate and abscissa indicate depth $(\mathrm{m})$ and mol percentages of each monosaccharide component. The profiles of each uronic acid (galacturonic acid $(\bullet)$

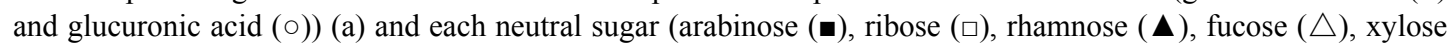
$(\diamond)$, mannose $(\diamond)$, galactuose $(\bullet)$ and glucose $(\circ))$ (b and c). The abscissa of the third figure (c) is zoomed to show the minor components. 


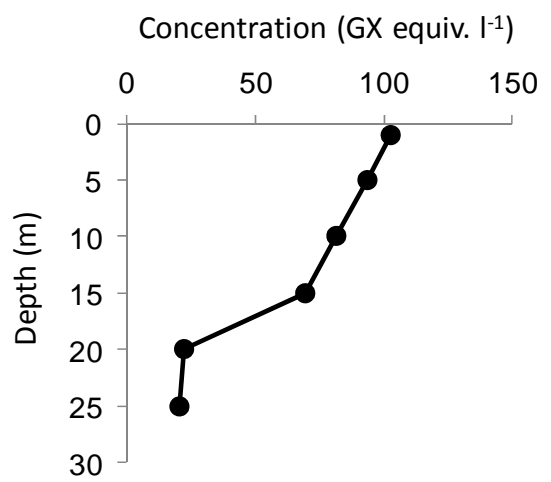

Figure 3. Vertical profile of the concentration of TEP. The ordinate and abscissa indicate depth $(\mathrm{m})$ and concentrations (GX equiv. $1^{-1}$ ) of TEP.

\section{ACKNOWLEDGEMENTS}

We wish to thank the crews for the Toyoshio-Maru research cruise (University of Hiroshima). The study was supported by grants from the Ministry of Education, Culture, Sports, Science and Technology, Japan (Nos. 14340166 and 19310003) and a Sasakawa Scientific Research Grant from the Japan Science Society. We are also grateful to the staff of Chemical Analysis Center (University of Tsukuba) for their help with GC/MS analysis.

\section{REFERENCES}

[1] Hama, T. and Yanagi, K. (2001) Production and neutral aldose composition of dissolved carbohydrates excreted by natural marine phytoplankton populations. Limnology and Oceanography, 46, 1945-1955. doi: $10.4319 / 10.2001 .46 .8 .1945$

[2] Amon, R.M.W. and Benner, R. (2003) Combined neutral sugars as indicators of the diagenetic state of dissolved organic matter in the Arctic Ocean. Deep Sea Research Part I, 50, 151-169. doi:10.1016/S0967-0637(02)00130-9

[3] Hama, T., Yanagi, K. and Hama, J. (2004) Decrease in molecular weight of photosynthetic products of marine phytoplankton during early diagenesis. Limnology and Oceanography, 49, 471-481. doi:10.4319/10.2004.49.2.0471

[4] Hernes, P.J., Hedges. J.I., Peterson, M.L., Wakeham, S.G. and Lee, C. (1996) Neutral carbohydrate geochemistry of particulate material in the central equatorial Pacific. Deep Sea Research Part II, 43, 1181-1204. doi:10.1016/0967-0645(96)00012-4

[5] Hamanaka, J., Tanoue, E., Hama, T. and Handa, N. (2002) Production and export of particulate fatty acids, carbohydrates and combined amino acids in the euphotic zone. Marine Chemistry, 77, 55-69. doi:10.1016/S0304-4203(01)00075-5

[6] Panagiotopoulos, C. and Sempéré, R. (2005) The molecular distribution of combined aldoses in sinking particles in various oceanic conditions. Marine Chemistry, 95, 3149. doi:10.1016/j.marchem.2004.07.005
[7] Decho, A.W. (1990) Microbial exopolymer secretions in ocean environments: Their role(s) in food webs and marine processes. Oceanography and Marine Biolology Annual Review, 28, 73-153.

[8] Bhaskar, P.V. and Bhosle, N.B. (2005) Microbial extracellular polymeric substances in marine biogeochemical processes. Current Science, 88, 45-53.

[9] Engel, A. (2000) The role of transparent exopolymer particles (TEP) in the increase in apparent particle stickiness $(\alpha)$ during the decline of a diatom bloom. Journal of Plankton Research, 22, 485-497. doi:10.1093/plankt/22.3.485

[10] Alldredge, A.L., Passow, U. and Logan, B.E. (1993) The abundance and significance of a class of large, transparent organic particles in the ocean. Deep Sea Research Part I, 40, 1131-1140. doi:10.1016/0967-0637(93)90129-Q

[11] Passow, U. (2002) Transparent exopolymer particles (TEP) in aquatic environments. Progress in Oceanography, $\mathbf{5 5}$ 287-333. doi:10.1016/S0079-6611(02)00138-6

[12] Logan, B.E., Passow, U., Alldredge, A.L., Grossart, H.-P. and Simon, M. (1995) Rapid formation and sedimentation of large aggregates is predictable from coagulation rates (half-lives) of transparent exopolymer particles (TEP). Deep Sea Research Part II, 42, 203-214. doi:10.1016/0967-0645(95)00012-F

[13] Passow, U. and Alldredge, A.L. (1999) Do transparent exopolymer particles (TEP) inhibit grazing by the euphasiid Euphausia pacifica? Journal of Plankton Research, 21, 2203-2217. doi:10.1093/plankt/21.11.2203

[14] Verdugo, P., Alldredge, A.L., Azam, F., Kirchman, D.L., Passow, U. and Santschi, P.H. (2004) The oceanic gel phase: A bridge in the DOM-POM continuum. Marine Chemistry, 92, 67-85. doi:10.1016/i.marchem.2004.06.017

[15] Panagiotopoulos, C. and Sempéré, R. (2005) Analytical methods for the determination of sugars in marine samples: A historical perspective and future directions. Limnology and Oceanography Methods, 3, 419-454. doi:10.4319/lom.2005.3.419

[16] Blake, J.D. and Richards, G.N. (1968) Problems of lactonisation in the analysis of uronic acids. Carbohydrate Research, 8, 275-281. doi:10.1016/S0008-6215(00)82233-8

[17] Chambers, R.E. and Clamp, R.E. (1971) An assessment of methanolysis and other factors used in the analysis of carbohydrate-containing materials. Biochemical Journal, 125, 1009-1018.

[18] Doco, T., O’Neill, M.A. and Pellerin, P. (2001) Determination of the neutral and acidic glycosyl-residue compositions of plant polysaccharides by GC-EI-MS analysis of the trimethylsilyl methyl glycoside derivatives. Carbohydrate Polymers, 46, 249-259. doi:10.1016/S0144-8617(00)00328-3

[19] Mejanelle, P., Bleton, J., Tchapla, A. and Goursaud, S. (2002) Gas chromatography-mass spectrometric analysis of monosaccharides after methanolysis and trimethylsilylation. Potential for the characterization of substances of 
vegetal origin: Application to the study of museum objects. Journal of Chromatography Library, 66, 845-902. doi:10.1016/S0301-4770(02)80049-5

[20] Passow, U. and Alldredge, A.L. (1995) A dye-binding assay for the spectrophotometric measurement of transparent exopolymer particles (TEP). Limnology and Oceanography, 40, 1326-1335. doi:10.4319/10.1995.40.7.1326

[21] Borch, N.H. and Kirchman, D.L. (1997) Concentration and composition of dissolved combined neutral sugars (polysaccharides) in seawater determined by HPLC-PAD. Marine Chemistry, 57, 85-95. doi:10.1016/S0304-4203(97)00002-9

[22] Myklestad, S.M., Sånøy, E.and Hestmann, S. (1997) A sensitive and rapid method for analysis of dissolved mono- and polysaccharides in seawater. Marine Chemistry, 56, 279-286. doi:10.1016/S0304-4203(96)00074-6

[23] Skoog, A. and Benner, R. (1997) Aldoses in various size fractions of marine organic matter: Implications for carbon cycling. Limnology and Oceanography, 42, 18031813. doi:10.4319/1o.1997.42.8.1803

[24] Kirchman, D.L., Meon, B., Ducklow, H.W., Carlson, C.A., Hansell, D.A. and Steward, G.F. (2001) Glucose fluxes and concentrations of dissolved combined neutral sugars (polysaccharides) in the Ross Sea and Polar Front Zone, Antarctica. Deep Sea Research Part II, 48, 41794197. doi:10.1016/S0967-0645(01)00085-6

[25] Benner, R. (2002) Chemical composition and reactivity. In: Hansell, D.A. and Carlson, C.A., Eds., Biogeochemistry of Marine Dissolved Organic Matter, Academic Press, San Diego, 59-90. doi:10.1016/B978-012323841-2/50005-1

[26] Pakuski, J.D. and Benner, R. (1994) Abundance and distribution of carbohydrates in the ocean. Limnology and Oceanography, 39, 930-940. doi:10.4319/10.1994.39.4.0930

[27] Amon, R.M.W., Fitznar, H.-P. and Benner, R. (2001) Linkage among the bioreactivity, chemical composition, and diagenetic state of marine dissolved organic matter. Limnology and Oceanography, 46, 287-297. doi:10.4319/10.2001.46.2.0287

[28] Hung, C-C., Guo, L., Santschi, P.H., Alvarado-Quiroz, N. and Haye, J.M. (2003) Distribution of carbohydrate species in the Gulf of Mexico. Marine Chemistry, 81, 119135. doi:10.1016/S0304-4203(03)00012-4

[29] Khodse, V.B., Fernandes, L., Bhosle, V.V., Fernandes, V., Matondkar, S.G.P. and Bhushan, R. (2007) Distribution and seasonal variation of concentrations of particulate carbohydrates and uronic acids in the northern Indian Ocean. Marine Chemistry, 103, 327-346. doi:10.1016/j.marchem.2006.10.003

[30] Manners, D.J. and Sturgeon, R.J. (1982) Reserve carbohydrates of algae, fungi, and lichens. In: F. A. Loewus and W. Tanner, Eds., Intracellular Carbohydrates, SpringerVerlag, Berlin, 472-514.

[31] Hanamachi, Y., Hama, T. and Yanai, T. (2008) Decomposition process of organic matter derived from freshwater phytoplankton. Limnology and Oceanography, 9, 57 69.

[32] Simon, M., Grossart, H-P., Schweitzer, B. and Ploug, H. (2002) Microbial ecology of organic aggrefates in aquatic ecosystems. Aquatic Microbial Ecology, 28, 175-211. doi:10.3354/ame028175

[33] Ramus, J. (1977) Alcian blue: A quantitative aqueous assay for algal acid and sulfated polysaccharides. Journal of Phycology, 13, 345-348.

[34] Mopper, K. (1977) Sugars and uronic acids in sediment and water from the Black Sea and North Sea with emphasis on analytical techniques. Marine Chemistry, 5, 585603. doi:10.1016/0304-4203(77)90044-5

[35] Zhou, J. and Mopper, K. (1998) The role of surface-active carbohydrates in the formation of transparent exopolymer particles by bubble adsorption of seawater. Limnology and Oceanography, 43, 1860-1871. 